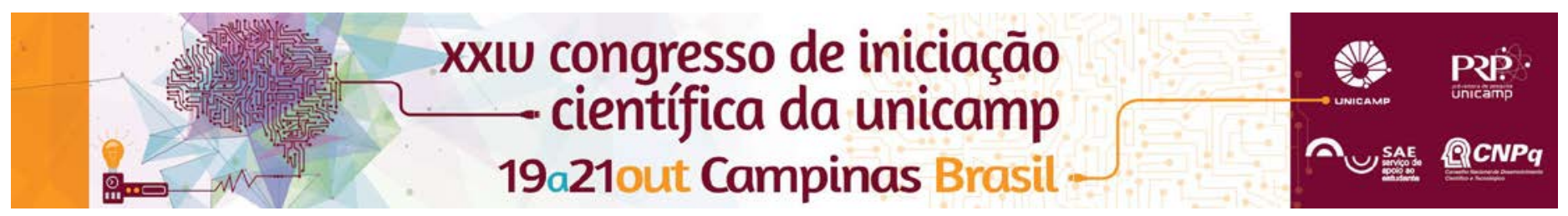

\title{
CV CO-OCCURRENCE IN THE ACQUISITION OF BRAZILIAN PORTUGUESE (BP) IN TWO CHILDREN BETWEEN THE AGES OF 0:6 TO 2:0
}

\author{
Mariana Hungria* (IC) , Eleonora Cavalcante Albano (PQ)
}

\begin{abstract}
There has been a lot of work on the question of consonant-vowel co-occurrence in language acquisition (e.g., MACNEILAGE \& DAVIS,1995). However, few writers have addressed this question in the Romance languages. The aim of this project is to explore CV co-occurrence in the acquisition of Brazilian Portuguese (BP) in two children between the ages of 0:6 and 2:0. The data were collected with a digital voice recorder, transcribed with the aid of acoustic analysis software and processed with a syllable counting software developed by the author. Our results so far indicate that there is prevalence of labial consonants and central vowel combinations as well as persistence of laryngeal sounds throughout the first year of age. We have attempted to increase our sample size in order to elucidate these questions. We have based our analysis in Articulatory Phonology (FAR) and on John Esling's work on laryngeals (MOISIK \& ESLING, 2007).
\end{abstract}

\section{Key words:}

CV co-occurrence, Articulatory Phonology, Language Acquisition

\section{Introduction}

The language acquisition literature reports stable biases in the combination of $\mathrm{C}$ and $\mathrm{V}$ sounds during the babbling and first word phases in many languages. These patterns have been explained phonologically or through dynamic and biomechanical models. The two major theories that focus on this issue are Articulatory Phonology (FAR) and Frame/Content theory (F/C). This project aims at raising further issues on this topic by means of data from two Brazilian Portuguese speaking children between the ages of $0: 6$ and 2:0.

\section{Results and Discussion}

Contrary to the literature, we have observed persistence of laryngeals occurring with all types of vowels beyond the first year of life. Later combinations involve labial consonants and central vowels (P1=30,53\% - P2=52,87\%)*. However, the occurrence of coronal consonants with front vowels was notably lower $(\mathrm{P} 1=1,58 \%$ - $\mathrm{P} 2=2,30 \%)$. Dorsal consonants and back vowel combinations were practically absent.

The rate of occurrence of syllables with laryngeals in the second year was sizable ( $P 1=36,32 \%$ - $P 2=9,20 \%$ ). This could indicate the existence of a transition phase between the patterns described by Esling and those reported by $\mathrm{F} / \mathrm{C}$.

The results also show that all consonants, laryngeal or buccal, prefer central vowels ( $\mathrm{P} 1=74,74 \%$ - $\mathrm{P} 2=73,56 \%)$. P1 uses all three vowel classes with laryngeals and coronals, whereas P2 only shows this diversity with labials ( $P 1=20,00 \%$ - $P 2=9,20 \%)$, the most frequent consonant class in the second year.

The high incidence of the pharyngeal vowel [a] in all combinations indicates an overall prevalence of laryngeal (glottal and pharyngeal) segments (P1=46,32\% $\mathrm{P} 2=60,92 \%)$. However, there is evidence of gradual buccalization in that labials and coronals predominate among consonants.
Table 1. Percentages (P1)

\begin{tabular}{lccccc}
\multicolumn{5}{c}{ Participant 1 } & Percentage \\
& LAB. & COR. & DOR. & LAR. & TOTAL \\
Front & $0,00 \%$ & $1,58 \%$ & $1,58 \%$ & $6,32 \%$ & $9,47 \%$ \\
Central & $30,53 \%$ & $24,21 \%$ & $0,00 \%$ & $20,00 \%$ & $74,74 \%$ \\
Back & $5,26 \%$ & $0,53 \%$ & $0,00 \%$ & $10,00 \%$ & $15,79 \%$ \\
Total & $35,79 \%$ & $26,32 \%$ & $1,58 \%$ & $36,32 \%$ & $100,00 \%$
\end{tabular}

Table 2. Percentages (P2)

\begin{tabular}{lccccc}
\multicolumn{5}{c}{ Participant 2 } & - Percentage \\
& LAB. & COR. & DOR. & LAR. & TOTAL \\
Front & $13,79 \%$ & $2,30 \%$ & $1,15 \%$ & $0,00 \%$ & $17,24 \%$ \\
Central & $52,87 \%$ & $9,20 \%$ & $2,30 \%$ & $9,20 \%$ & $73,56 \%$ \\
Back & $9,20 \%$ & $0,00 \%$ & $0,00 \%$ & $0,00 \%$ & $9,20 \%$ \\
Total & $75,86 \%$ & $11,49 \%$ & $3,45 \%$ & $9,20 \%$ & $100,00 \%$
\end{tabular}

\section{Conclusions}

Our results so far are only marginally consistent with the mainstream literature. However, they are in line with Esling's claims about the first year of life. As the literature does not provide any description of buccalization, our results can be taken as preliminary evidence that this process differs somewhat in vowels and consonants. Vowel buccalization seems to progress from the pharynx to the front and then to the back of the tongue, whereas consonant buccalization seems to progress from the lips to the tongue tip and then to the dorsum.

\section{Acknowledgement}

We thank CNPq and PRP-Unicamp for their support.

DAVIS, B.L., MACNEILAGE, P.F. The articulatory basis for babbling Journal of Speech and Hearing Research, 38(6), p.1199-1211, 1995. MOISIK, S. R.; ESLING, J. H. 3-D auditory-articulatory modeling of the laryngeal constrictor mechanism. In: TROUVAIN, J.; BARRY, W. J. (orgs.), Proceedings of the 16th International Congress of Phonetic Sciences, Saarbrücken: Universität des Saarlandes, v. 1, p. 373-376, 2007. 